\title{
Ultraviolet Photodissociation of Protonated, Fixed Charge, and Charge-Reduced Peptides
}

\author{
Dustin D. Holden ${ }^{a}$, Jeff M. Pruet ${ }^{b}$, Jennifer S. Brodbelt ${ }^{a *}$
}

${ }^{a}$ Department of Chemistry, 1 University Station A5300, University of Texas at Austin, Austin, TX 78712

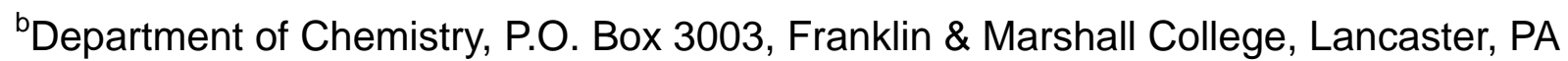
17604

“Corresponding author: Jennifer S. Brodbelt, jbrodbelt@cm.utexas.edu 


\section{Abstract}

The fragmentation behavior of three peptides (RGAFSTFGAS, GAFSTFGASR, and GAFSTFGASS) was evaluated by collisional activated dissociation (CAD), higher energy collisional activated dissociation (HCD), and ultraviolet photodissociation (UVPD). In particular, hybrid methods combining electron transfer with CAD, HCD, or UVPD were used to assess the impact of the location of a basic site at the $\mathrm{C}$ - or $\mathrm{N}$-terminus, the presence of a fixed charge at the $\mathrm{C}$ - or $\mathrm{N}$-terminus, and the presence of a radical site. The release of a mobilized proton occurred for those peptides modified with a quaternary amine at the $\mathrm{C}$ - or N-terminus, thus resulting in formation of $\mathrm{C}$ - and/or $\mathrm{N}$-terminus fragment ions that would not otherwise be expected if the fixed charge remained static. Activation of charge-reduced peptides (i.e. peptide radical ions) resulted in simplified spectra compared to the corresponding even electron peptides. Interestingly, UVPD of the charge-reduced species generated similar spectra to CAD and HCD of the same precursor ions, suggesting a shift to dominant radical-induced dissociation rather than the more diverse pathways common upon photodissociation.

Keywords:

Hybrid activation

Ultraviolet photodissociation

Electron transfer

Fixed charge

Collisional activation

Quaternary amine 


\section{Introduction}

Bottom-up proteomic strategies that rely on proteolytic digestion of proteins and tandem mass spectrometry to characterize the resulting peptides are the most popular approaches for implementation of high throughput, broad-scale identification of proteins in complex mixtures [13]. The typical bottom-up workflow has proven successful for identifying hundreds to thousands of proteins in complex mixtures based on matching peptides to proteins via in silico database search algorithms. The foundation of the database search algorithms is largely based on the ability to generate accurate theoretical tandem mass spectra based on predictive rules of peptide fragmentation [4-7]. Understanding the factors that modulate peptide dissociation remains an important challenge in developing the best correlations between experimental MS/MS spectra and in silico predictions. Both the location and type of peptide charge sites, as well as the ion activation method, influence the resulting fragmentation patterns. Bottom-up protocol commonly involves proteolytic digestion using trypsin, cleaving peptide bonds at basic lysine and arginine residues [8]. The presence of basic amino acids can alter MS/MS fragmentation patterns by sequestering a proton [5], thus reducing proton mobility and simplifying fragmentation spectra. Others have noted the enhancement of specific peptide backbone cleavage sites, such as cleavages adjacent to acidic residues and at the $\mathrm{N}$-terminal side of proline, among others, which lead to prominent fragment ions in the MS/MS spectra of protonated peptides [6-9].

Attaching fixed charges to peptides through derivatization, originally as a means to enhance ionization efficiencies $[10,11]$, has been shown by a number of groups to modulate the formation of $\mathrm{N}$ - and $\mathrm{C}$-terminal fragment ions via charge-remote mechanisms [10-33]. It was noted that the resulting fixed-charge peptides exhibited differences in their fragmentation behavior compared to the analogous non-fixed charge counterparts. For example, the Reilly group has investigated several fixed charge reagents and found that the presumed fixed charge site of a quaternary amine modification can cleave generating a mobile proton, which may lead 
to fragment ions that do not originate from the terminus of the original fixed charge site [12]. Another fixed charged reagent, tris(2,4,6-trimethoxy phenyl)phosphonium acetyl (TMPP), did not result in a similar mobile proton effect upon collision activated dissociation (CAD). High energy ultraviolet photodissociation (UVPD) using $157 \mathrm{~nm}$ photons of TMPP-tagged peptides promoted consistent charge-remote fragmentation [13]. Affixing a fixed charge tag to the $\mathrm{N}$ terminus of a peptide has also been reported to improve sequence coverage obtained by electron transfer dissociation (ETD) for tryptic-like peptides (ones containing arginine at the Cterminus) [14]. Thus, evidence for variations in peptide fragmentation patterns has been correlated with the type of charge site (e.g. fixed charge versus mobile proton), the locations of charge sites (e.g. C-terminus, N-terminus, side-chain, backbone site), and the nature of the energization (e.g. low energy step-wise CAD versus high energy UVPD).

Whether the peptides are odd electron radical ions or even electron species is an additional mitigating factor that has generated considerable interest in recent years with the emergence of electron-activated dissociation methods: electron capture dissociation (ECD) $[34,35]$ and electron transfer dissociation (ETD) [36,37]. Electron-activated methods lead to peptides with an extra electron via an exothermic electron transfer process that facilitates radical-induced dissociation and production of $c$-/z-type fragment ions that contrast to the conventional $b$-/y-type fragment ions generated by collision-based methods. Although the electron-activated methods often favor the formation of non-dissociated charge-reduced precursor ions (i.e. ETnoD), fragmentation efficiency has been significantly enhanced by applying supplemental energy or by following electron-activation with an auxiliary activation method $[38,39]$. Because of the greater propensity of ions in low charge states to undergo charge reduction rather than fragmentation into $c / z$ ions, a number of groups have developed means to increase the charge states of ions via using super-charging ESI conditions or by covalent attachment of fixed charge sites [40-43]. 
"Hybrid" activation methods combine electron transfer reactions with CAD, higher-energy collisional dissociation (HCD), infrared multiphoton dissociation (IRMPD) or UVPD and have been reported to circumvent some of the potential charge-dependent shortcomings of ECD or ETD alone to generate richer fragmentation patterns [38,39,44-51]. UVPD has been previously shown to produce rich fragmentation patterns alone compared to other methods [52,55-72]. We have previously used $193 \mathrm{~nm}$ UVPD to explore the fragmentation of radical peptide cations generated by ETnoD [52]. A key feature that influenced the types of products was the position of the charge site as evidenced by the location of a sequestered proton (via a basic Arg residue) at either the $\mathrm{N}$ - or $\mathrm{C}$-terminus. A recent study utilized ETD and subsequent activation by CAD or UVPD to determine the impact of the location of a specific amino acid (serine) within a peptide sequence on the resulting peptide fragmentation patterns [53]. For peptides containing histidine, electron transfer reactions caused a chromophore effect that specifically enhanced absorption of $355 \mathrm{~nm}$ photons [54]. We have recently reported an increase in sequence information obtained for intact proteins by combining ETD and $193 \mathrm{~nm}$ UVPD to produce more evenly distributed fragment ion types [44], in contrast to the dominant a-type fragment ions observed upon UVPD alone [55,56].

In the present study we evaluate the variations in fragmentation of fixed-charge peptides in comparison to analogous peptides containing a highly basic, proton-sequestering arginine at either the $\mathrm{N}$ - or $\mathrm{C}$-terminus. The three reactions used to attach fixed charges are shown in Scheme 1. Three methods, CAD, HCD, and UVPD, are used to characterize the conventional protonated and fixed-charge peptides, and three hybrid activation methods, ETcaD, EThcD, and ETuvPD, are used to produce and analyze the corresponding peptide radical ions after charge reduction. To explore the impact of the location and type of charge on the fragmentation pathways of peptides, three peptides (RGAFSTFGAS, GAFSTFGASR, and GAFSTFGASS) were evaluated. Two of these peptide sequences were specifically designed to have a highly basic site (Arg) at the $\mathrm{N}$ - or $\mathrm{C}$ - terminus, and the third was an analogous peptide with no basic 
site. For all three peptides, the remainder of the peptide sequence was kept constant to mitigate the impact of other residue-specific effects. In the present study, it is shown that simplified spectra are produced by photodissociation of the charge-reduced fixed-charge peptides generated by ETnoD.

\section{Experimental}

\subsection{Materials}

N,N-Dimethylformamide (DMF), HPLC grade water, methanol and acetonitrile were obtained from Fisher Scientific (Pittsburgh, PA, USA). N-(3-Dimethylaminopropyl)-N'ethylcarbodiimide hydrochloride (EDC) and 1-hydroxy-7-azabenzotriazole (HOAt) were purchased from AAPPTec, LLC (Louisville, KY, USA). N-Succinimidyl [tris(2,4,6trimethoxyphenyl)phosphonio]acetate bromide (TMPP-AC-OSu) was obtained from Toronto Research Chemicals Inc. (Toronto, ON, CAN). Girard's Reagent T and trifluoroacetic acid were obtained from Sigma-Aldrich (St. Louis, MO, USA). Peptides RGAFSTFGAS, GAFSTFGASR, and GAFSTFGASS, were synthesized in-house using solid phase reaction and Fmoc amino acids from Novabiochem (Billerica, MA, USA).

\subsection{Fixed Charge Derivatization of Peptides}

Aliquots of each peptide were derivatized to contain a phosphonium N-terminal fixed charge via reaction with TMPP-AC-OSu using a previously described method (see Scheme 1A) [13]. The molar stoichiometric ratio of the reaction was reduced to $5: 1$ (reagent:peptide) to decrease the residual TMPP that carried over after $\mathrm{C}_{18}$ cleanup. An additional peptide $\mathrm{N}$ terminus fixed charge reagent, trimethyl-ammonium butyric acid with an amine-reactive $\mathrm{N}$ hydroxysuccinimide group (TMAB-NHS), was synthesized in-house according to a previously reported method [30]. TMAB-NHS was reacted in a 5:1 stoichiometric ratio (reagent:peptide) in $0.2 \mathrm{M} \mathrm{NaHCO}_{3}$ in $20 \%$ acetonitrile, $\mathrm{pH}=9$, using the reaction procedure also used to derivatize 
peptides with TMPP-AC-OSu (see Scheme 1B) [13]. Quaternary amine fixed charges were attached to the C-termini of peptides by incubating a $100 \mu \mathrm{L}$ aliquot of peptide $(1 \mathrm{mM})$ in water with $100 \mu \mathrm{L}$ of $10 \mathrm{mg} / \mathrm{mL}$ Girard's Reagent T (in 50\% DMF). The reaction entailed mixing 100 $\mu \mathrm{L}$ of $15 \mathrm{mg} / \mathrm{mL}$ EDC in DMF, $100 \mu \mathrm{L}$ of $15 \mathrm{mg} / \mathrm{mL}$ HOAt in DMF, and $30 \mu \mathrm{L}$ of $10 \%$ TFA for a net $\mathrm{pH}$ of 6 (see Scheme 1C). The mixture was allowed to react for 12 hours at $35^{\circ} \mathrm{C}$ and dried under vacuum overnight. The resulting derivatized peptides were desalted using standard SPE $\mathrm{C}_{18}$ clean-up procedures.

\subsection{Instrumentation and data collection}

Derivatized and underivatized peptides were diluted to $1 \mu \mathrm{M}$ with methanol/water/formic acid $(70 / 30 / 0.1, v / v / v)$ before direct infusion into a Thermo Fisher Scientific Orbitrap Elite mass spectrometer (Bremen, Germany) modified to allow UVPD in the HCD cell as described previously [55]. A $500 \mathrm{~Hz}$ Coherent ExciStar ArF (193 nm, $5 \mathrm{nsec}$ per pulse) excimer laser (Santa Clara, CA, USA) was used for UVPD. The ion trap control language (ITCL) was customized to allow $\mathrm{MS}^{3}$ combining $\mathrm{ET}$ reactions and UVPD. Hybrid $\mathrm{MS}^{3}$ activation was undertaken by performing ETD of the +2 charge state precursor in the linear ion trap, followed by CAD (also in the linear ion trap), HCD (in the HCD cell), or UVPD (in the HCD cell) of the resulting isolated charge-reduced species. For comparisons of MS/MS behavior, CAD, HCD, and $193 \mathrm{~nm}$ UVPD spectra of each singly protonated or fixed-charge peptide were collected. The CAD parameters were as follows: 23 - 35 NCE, activation time of $10 \mathrm{~ms}$, and an activation q of 0.25 . The HCD parameters were as follows: $23-38$ NCE, activation time of $0.10 \mathrm{~ms} .193$ nm UVPD was undertaken by exposing the ions to $4-8$ laser pulses at 2 - $3 \mathrm{~mJ}$ per pulse. The laser pulses were applied at $500 \mathrm{~Hz}$ during an 8 - $16 \mathrm{~ms}$ activation period.

\section{Results}

The fragmentation patterns of three peptides RGAFSTFGAS, GAFSTFGASR, and GAFSTFGASS were compared. A fixed charge was attached at either termini, and each one 
analyzed as either a singly protonated species (those not modified with a fixed charge tag), a fixed charge ion (not protonated; the charge is appended via the phosphonium TMPP+ or a quaternary amine $\mathrm{QA}+$ ), or a charge-reduced protonated radical ion (formed via an electron attachment reaction of a protonated species). The peptide radical ions were generated in the dual-pressure linear ion trap of the Orbitrap Elite mass spectrometer through electron transfer (ET) reactions of the doubly charged peptides initially generated by ESI, resulting in chargereduced peptide radical ions (i.e. initially $2+$ but with an extra electron attached) [38]. Subsequent activation of the resulting peptide ions was undertaken either in the high pressure trap (CAD) or in the HCD cell (for HCD or UVPD). Whether protonated, fixed charge, or chargereduced, in each case the net charge state of the precursor ion was $1+$, thus maintaining charge parity throughout the study. Representative examples of the MS/MS spectra are shown in

\section{Figures 1 - 5 and Supplemental Figures 1 - 4.}

\subsection{Unmodified Peptides}

As initial benchmark data, examples of the UVPD spectra obtained for singly protonated peptides containing a basic amino acid (arginine) at the $\mathrm{N}$ - or $\mathrm{C}$-terminus are shown in Figure 1, and the corresponding ETuvPD spectra (i.e. formation and analysis of the charge-reduced peptides) are shown in Figure 2. The UVPD mass spectra of protonated peptides are rich, containing $a, b, c, x, y$, and $z$ ions, as well as side-chain loss ions $(d, v)$. Neutral losses of water or ammonia from these primary fragment ions are also observed. These types of complicated fragmentation patterns are one of the hallmarks of UVPD and are attributed to the multiple mechanisms of UVPD, occurring both directly from excited states and after intramolecular vibrational redistribution after internal conversion [57,73]. As expected, the presence of the terminal arginine shifts the distribution of $\mathrm{N}$ - and C-terminal fragments due to proton sequestration [5]. The presence of an N-terminal arginine results in production of solely $\mathrm{N}$ terminal fragments $(a, b, c, d)$ (Figure 1A), whereas a C-terminal arginine results in predominantly 
C-terminal fragments $(v, x, y, z)$ and a few $b$ ions (Figure 1B). For the peptide lacking an arginine, a more even distribution of $\mathrm{N}$-terminal and $\mathrm{C}$-terminal ions was observed (Figure 1C).

The analogous CAD and HCD spectra for each of the three singly protonated peptides are shown in Supplemental Figures 1, 2, and 3. CAD spectra of the peptides that contained an $\mathrm{N}$ - or C-terminal arginine (Supp. Figures $\mathbf{1 A}$ and $\mathbf{2 A}$ ) followed previous trends of dominant loss of $\mathrm{NH}_{3}$ from the protonated arginine side-chain [7]. HCD spectra of those same peptides (Supp. Figures 1B and 2B) showed higher conversion efficiencies of precursor to backbone fragment ions. As expected, $\mathrm{CAD}$ and $\mathrm{HCD}$ of the $\mathrm{N}$-terminal arginine peptide generated $\mathrm{N}$ terminal fragment ions; CAD and HCD of the C-terminal arginine peptide generated a mixture of $\mathrm{N}$ - and $\mathrm{C}$-terminal fragments due to the possibility of two protonation sites ( $\mathrm{N}$-terminal amine and Arg). CAD and HCD of GAFSTFGASS produced a mixture of $\mathrm{N}$ - and C-terminal fragments (Supp. Figure 3).

The UVPD mass spectra of the corresponding charge-reduced peptides are shown in Figure 2. In this case, doubly protonated peptides $(2+)$ were subjected to electron transfer reactions to generate charged-reduced species, then the charged-reduced peptides $\left(1+{ }^{*}\right)$ were subjected to UVPD (in a net hybrid process termed ETuvPD). The fragmentation patterns were generally much simpler than the patterns of the conventional protonated peptides in terms of the number of fragment ions produced, displaying mainly $c$ - and $z$-type ions, ones traditionally observed upon electron activation. For all three peptides and their fixed charge analogs, this spectral simplification was especially true for ETuvPD (in comparison to ETcaD and EThcD) for which the number of different fragment ions typically decreased by $\sim 50 \%$ for the chargereduced peptides.

We were particularly interested in evaluating the impact on the UVPD behavior of fixed charge attachment to these peptides in comparison to conventional protonation, in addition to assessing the impact of charge-reduction of the peptides by electron attachment, yielding odd 
electron peptides. Comparative examples of the UVPD spectra for the resulting peptide ions are shown in Figures 3, 4, 5, Supplemental Figure 4, and summarized in Figure 6 and Table 1, with key results described in the following sections.

\subsection{N-Terminal Arginine (RGAFSTFGAS)}

Examples of the UVPD mass spectra for the C-terminal quaternary amine fixed-charge peptide RGAFSTFGAS-QA ${ }^{+}$are shown in Figure 3. This is an interesting peptide since the basic Arg residue at the $\mathrm{N}$-terminus is known to sequester a proton (resulting in the predominance of $\mathrm{N}$-terminal fragment ions observed in Figure 1A), whereas the attachment of the fixed charge quaternary amine at the C-terminus localizes a single charge at the opposite end of the peptide. UVPD of the fixed-charge peptide results in a mixture of $\mathrm{N}$ - and $\mathrm{C}$-terminal fragments although a prominent neutral loss of trimethylamine (-59 Da) and addition neutral loss of $\mathrm{CO}(-87 \mathrm{Da})$ occurred (Figure $\mathbf{3 A})$. These latter pathways were also dominant in the CAD and HCD spectra (spectra not shown, see Table 1). UVPD of the corresponding chargedreduced peptide resulted in a substantially simplified spectrum (Figure 3B), comprised of only $c$ - and $z$-type fragment ions which are radical-mediated products commonly observed upon ETD. The $z$-type ions are more abundant than the $c$-type, suggesting greater retention of the charge at the C-terminus, and there is a notable reduction in the loss of trimethylamine that was a dominant process upon UVPD of the even electron fixed-charge peptide (Figure 3A).

Attachment of a quaternary amine tag to the N-terminus of peptide RGAFSFGAS resulted in a fixed-charge peptide (QA+-RGAFSFGAS) in which the loss of trimethylamine was dominant upon CAD, HCD or UVPD, as summarized in Table 1A. In addition, UVPD generated over $20 \mathrm{~N}$-terminal fragment ions $(a, b, c)$, which are summarized in the top section of Figure $6 \mathrm{C}$ and Table 1A. In contrast to the prominent loss of trimethylamine for $\mathrm{QA}^{+}-\mathrm{RGAFSFGAS}$ upon CAD or HCD, ETcaD and EThcD (i.e. interrogation of the odd electron peptide created after electron attachment to the protonated fixed-charge peptide) resulted in a series of diagnostic $c$ 
and $z$ ions (Table 1A). ETuvPD produced a similar series of $c / z$ ions (Table 1A), but the total number of different fragment ions (8 fragment ions) was significantly lower in comparison to UVPD of the even electron fixed-charge peptide (20 fragment ions) (Figure 6C).

A second $\mathrm{N}$-terminal fixed-charge peptide was generated by attachment of the TMPP tag to RGAFSTFGAS. Examples of UVPD and ETuvPD mass spectra for the resulting TMPP ${ }^{+}$ RGAFSTFGAS peptide are shown in Supplemental Figure 4, and the CAD, HCD, ETcaD, and EThcD results are summarized in Figure 6A, 6B and Table 1A. The even electron fixed-charge peptide dissociated predominantly by the loss of the charged TMPP tag (resulting in the TMPP ${ }^{+}$ ion of $\mathrm{m} / \mathrm{z} 573$ ) in addition to the formation of some low abundance TMPP-containing $\mathrm{N}$-terminal fragment ions (a,c,d ions) (Supplemental Figure 4A). UVPD of the corresponding odd electron charge-reduced peptide produced a series of $\mathrm{N}$-terminal $c$ ions, giving nearly full sequence coverage, with a significant reduction in the abundance of the TMPP tag ion (Supplemental

Figure 4B). The number and types of $\mathrm{N}$-terminal $c$ ions produced by ETcaD, EThcD, and ETuvPD for charge-reduced TMPP ${ }^{+}$-RGAFSTFGAS are summarized in the bottom sections of Figures $6 \mathrm{~A}, 6 \mathrm{~B}$, and $6 \mathrm{C}$, respectively, and in Table $1 \mathrm{~A}$, and were almost identical for all three hybrid methods. In general, attachment of the TMPP fixed charge tag to the N-terminus resulted in the exclusive formation of $\mathrm{N}$-terminal fragment ions for all peptides and for all activation methods as well as for both odd and even electron precursors.

\subsection{C-Terminal Arginine (GAFSTFGASR)}

The number and types (C-terminal versus $\mathrm{N}$-terminal) of fragment ions produced upon CAD, ETcaD, HCD, EThcD, UVPD, and ETuvPD for protonated GAFSTFGASR and its fixedcharged variants are summarized in the center sections of Figure 6 and Table 1B. Protonated or charge-reduced GAFSTFGASR produced a mixture of N-terminal and C-terminal fragment ions upon CAD, HCD, or UVPD, as summarized in the top section of Table 1B. Attachment of a quaternary ammonium fixed charge to the N-terminus (QA+-GAFSTFGASR) led to significant 
loss of trimethylamine upon UVPD (as noted previously for other quaternary amine-tagged peptides), as well as formation of an extensive array of $\mathrm{N}$ - and C-terminal fragment ions $(a, b, c, x, y, z)$ (Figure 4A). In contrast, UVPD of charge-reduced QA+-GAFSTFGASR resulted solely in $c$ and several $\mathrm{N}$-terminal a-type ions (Figure 4B).

UVPD of the peptide created by replacement of the quaternary amine tag by the TMPP fixed charge tag at the N-terminus (TMPP ${ }^{+}$-GAFSTFGASR) yielded only N-terminal fragment ions. The UVPD spectrum of the charge-reduced TMPP+-GAFSTFGASR is very similar to that of QA+-GAFSTFGASR: showing a series of $c$ and less abundant a-type ions. Moving the fixed charge to the C-terminus (GAFSTFGASR-QA ${ }^{+}$) led to the prominent loss of trimethylamine upon UVPD, in addition to low abundances of $\mathrm{N}$ - and $\mathrm{C}$-terminal fragment ions $(b, x, y, z)$. In contrast, UVPD of the charge-reduced peptide resulted solely in production of C-terminal $z$ ions, similar to those observed upon CAD or HCD of the same charge-reduced peptide.

\subsection{No Arginine (GAFSTFGASS)}

A final peptide containing no amino acids with basic side-chains, GAFSTFGASS, was evaluated. Upon UVPD of the protonated or charge-reduced peptide, both $\mathrm{N}$ - and C-terminal ions were produced; $a, b$, and $x, y$ for the protonated peptide and $c$ and $z$ for the charge-reduced peptide (top section of Table 1C). Attachment of a quaternary ammonium fixed charge to the $\mathrm{N}$-terminus (QA+-GAFSTFGASS) again yielded a prominent loss of trimethylamine upon UVPD, in addition to a substantial series of $\mathrm{N}$-terminal fragment ions $(a, b, c$,$) . UVPD of charge-reduced$ $\mathrm{QA}^{+}$-GAFSTFGASS likewise resulted solely in N-terminal product ions; however in this case only $a$ and $c$ ions, no $b$ ions, were formed (see Table 1C), and the number of different fragment ions was reduced by roughly a factor of three compared to UVPD of even electron $\mathrm{QA}^{+}$GAFSTFGASS (Figure 6C).

Substitution of the quaternary amine tag by the TMPP tag at the N-terminus $\left(\mathrm{TMPP}^{+}-\right.$ GAFSTFGASS) yielded nearly an identical series of UVPD fragment ions as observed upon 
UVPD of $\mathrm{QA}^{+}$-GAFSTFGASS (Table 1C). ETuvPD of the charge-reduced peptide also resulted in nearly identical fragmentation patterns for $\mathrm{QA}^{+}$-GAFSTFGASS and TMPP+-GAFSTFGASS. Moving the quaternary amine fixed charge to the C-terminus of the peptide resulted in an UVPD spectrum (Figure 5A) similar to that of the unmodified peptide (Figure 1C) for which both Cterminal and N-terminal fragments were produced. In contrast, ETuvPD of the charge-reduced GAFSTFGASS-QA ${ }^{+}$peptide resulted solely in a clean series of C-terminal $z$ ions in a manner consistent with radical-mediated pathways (Figure 5B).

\section{Discussion}

Table 1 provides a global summary of the types of fragmentation pathways observed for the peptides, in terms of formation of conventional sequence ions $(a, b, c, x, y, z)$, prominent neutral losses (-59 Da for those containing a quaternary trimethyl ammonium terminus), or formation of a significant TMPP ion (for the TMPP-modified peptides). Shown in Figure 6 is a bar-graph summary of the number of $\mathrm{N}$-terminal $(a, b, c)$ and $\mathrm{C}$-terminal $(x, y, z)$ fragment ions for the three peptides in their protonated, fixed charge, or odd electron charge-reduced forms. The presence of an $\mathrm{N}$-terminal arginine or an $\mathrm{N}$-terminal fixed charge led to the predominant formation of $\mathrm{N}$-terminal fragments for all activation methods, whereas the presence of a Cterminal arginine or C-terminal fixed charge produced more C-terminal fragments. In each case, $193 \mathrm{~nm}$ UVPD produced a greater number of diagnostic fragments compared to CAD or HCD for the protonated or fixed-charge peptides. For the charge-reduced peptides (ones produced by electron transfer), the number and types of fragment ions were very similar for all three activation methods: ETcaD, EThcD, and ETuvPD.

For RGAFSTFGAS, N-terminal fragments were always favored for the unmodified peptide and for both types of $\mathrm{N}$-terminal modified versions (TMPP ${ }^{+}$-RGAFSTFGAS and $\mathrm{QA}^{+}$RGAFSTFGAS), whether activated as even-electron or charge-reduced odd electron species (see Table 1A). However, for RGAFSTFGAS-QA ${ }^{+}$with a fixed charge at the C-terminus, both 
C- and N-terminal ions were observed for the charge-reduced peptides upon ETcaD, EThcD, UVPD, and ETuvPD. Elimination of trimethylamine (-59 Da, neutral tag loss) has also been previously shown as a prominent loss allowing a proton to be liberated in the process [12]. UVPD of singly charged RGAFSTFGAS and RGAFSTFGAS-QA ${ }^{+}$, Figures 1A and $\mathbf{3 A}$ respectively, resulted in formation of similar $\mathrm{N}$-terminal fragment ion series, along with a dominant tag loss in Figure 3A. The unexpected formation of $\mathrm{N}$-terminal product ions in Figure 3A despite the fixed charge at the C-terminus is rationalized through the elimination of trimethylamine which re-generates a mobile proton that may migrate to the $\mathrm{N}$-terminal Arg, via a process identical to that reported by Reilly et al. [12]. Although not shown, this neutral loss of trimethylamine was also observed for CID and HCD of the RGAFSTFGAS-QA ${ }^{+}$peptide, which supports the conclusion that this is not a radically driven neutral loss of an arginine side-chain [74] but rather due to a rearrangement, possibly involving cyclization with the N-terminal Arg, occurring when the fixed charge tag is lost.

For GAFSTFGASR and GAFSTFGASS, there was greater variation in whether C- or Nterminal fragments or both types were formed, and the outcome depended on the activation method (CAD, HCD versus UVPD). Activation of unmodified peptides resulted in a mixture of $C$ and $\mathrm{N}$-terminal fragments by CAD, HCD, and UVPD. Modification of these two peptides by attachment of TMPP at the $\mathrm{N}$-terminus resulted solely in formation of $\mathrm{N}$-terminal fragment ions, confirming the dominant role of the fixed charge on the fragmentation behavior. In contrast, addition of a quaternary amine at the N-terminus of GAFSTFGASR and GAFSTFGASS led to formation of both $\mathrm{C}$ - and $\mathrm{N}$-terminal ions, but yielded only $\mathrm{N}$-terminal ions for the chargereduced peptides. The quaternary amine tag underwent cleavage to eliminate trimethylamine and generate a mobile proton that facilitated formation of the unexpected $\mathrm{C}$ - or $\mathrm{N}$-terminal ions upon $\mathrm{CAD}$ and HCD despite the location of a charge-sequestering Arg residue. However, the Nterminal quaternary amine-tagged GAFSTFGASR and GAFSTFGASS peptides yielded only N- 
terminal ions for the charge-reduced species, cleavage of trimethylamine was no longer dominant, and the resulting fragment ions were dictated by radical-mediated pathways.

One of the most notable findings from the collection of results for the three peptides in the fixed-charge forms was the similarities of the fragmentation patterns, both in terms of number and types of fragment ions, obtained upon CAD, HCD and UVPD of the charge-reduced species (i.e. odd electron peptides). This result contrasted with the substantially greater diversity of fragment ions produced by UVPD relative to CAD and HCD for the protonated and fixedcharge peptides. Reference ETD spectra collected for the doubly-charged peptides (those with one proton and one fixed charge site) displayed $c$ or $z$ fragment ions depending on the location of the fixed charge site. Activation of charge-reduced peptide ions, whether by collisions or photons, led to the same $c$ and or $z$ ions observed upon ETD, thus recapitulating the dominance of the radical-mediated pathways regardless of activation method.

Since formation of a salt bridge between amino acids may occur for low charge states [75], the adoption of zwitterionic states was considered, especially in the context of the potential impact on fragmentation pathways. According to a previous study that evaluated the existence of zwitterionic peptides by UVPD, the competitive neutral loss of $45 \mathrm{Da}(\mathrm{COOH})$ versus $44 \mathrm{Da}$ $\left(\mathrm{CO}_{2}\right)$ allowed a means to quantify the portion of zwitterions [76]. Based on the $\mathrm{CO}_{2}$-loss factor equation where $\mathrm{K}_{\mathrm{CO} 2}=([-44]-[45]) /([-44]+[-45])[76]$, zwitterions yielded positive $\mathrm{K}_{\mathrm{CO} 2}$ values up to 1.0 , whereas non-zwitterions produced negative values down to -1.0 . For peptides that were modified at the C-terminus (quaternary amine, $\mathrm{QA}^{+}$) in the present study, the carboxylterminus was no longer free and thus zwitterion formation was not possible.

$\mathrm{K}_{\mathrm{CO} 2}$ values were calculated to assess the existence of zwitterionic states for unmodified peptides during $193 \mathrm{~nm}$ UVPD (Figure 1). UVPD of RGAFSTFGAS, GAFSTFGASR, and GAFSTFGASS yielded $\mathrm{K}_{\mathrm{CO} 2}$ values of $0.04,-0.27$, and 0.05 respectively. These values are quite small and do not indicate a large population of zwitterionic states. UVPD of chargereduced states of the unmodified peptides did not demonstrate losses of $45 \mathrm{Da}$ or $44 \mathrm{Da}$ loss 
from the precursor ion. In fact, UVPD of charge-reduced precursors with and without fixedcharge tags did not undergo substantial losses of $\mathrm{COOH}$ or $\mathrm{CO}_{2}$, presumably due to neutralization of a charged basic site (by electron transfer reaction) that would otherwise allow zwitterionic states.

Those peptides containing a fixed charge tag located on the $\mathrm{N}$-terminus afforded a greater opportunity for formation of zwitterionic states, as in Figures 4A and Supplemental Figure 4A. $\mathrm{K}_{\mathrm{CO} 2}$ values for each of these peptides were 0.49 and 0.53 , respectively. These positive values suggest that zwitterionic states may be adopted for those peptides with an $\mathrm{N}$ terminal quaternary amine fixed charge (QA+-GAFSTFGASR). Although not shown, CAD and HCD spectra of $\mathrm{QA}^{+}$-GAFSTFGASR contained dominant neutral losses of the trimethylamine ($59 \mathrm{Da})$ as well as a neutral loss of $\mathrm{CO}_{2}(-44 \mathrm{Da})$ characteristic of zwitterions.

Furthermore, UVPD of the peptide containing a phosphonium fixed charge tag attached to the N-terminus (TMPP+ ${ }^{+}$RGAFSTFGAS) generated a $\mathrm{K}_{\mathrm{CO} 2}$ value of 0.53 , one of the higher values found in the present study. The Reilly group observed the formation of $\mathrm{TMPP}^{+}$upon the loss of the tag from TMPP-tagged FSWGAEGQR and RFSWGAEGQ peptides, with the TMPP ${ }^{+}$ ion much more prominent for the peptide with the Arg at the $\mathrm{N}$-terminus [28]. For the latter, they suggested the possible formation of a salt bridge between the arginine side-chain and the Cterminal carboxylic acid group, forming a cyclized structure. Blocking the C-terminus by esterification resulted in little change in the prominent loss of the fixed charge tag, leading to the conclusion that the potential salt bridge was not responsible for enhancing the dominant loss of TMPP $^{+}$.

\section{Conclusions}

The influence of four key factors on the fragmentation patterns of peptides has been examined: i) location of a basic arginine residue site, ii) impact of a fixed charge, iii) conversion of conventional even electron peptides to odd electron peptides by electron transfer, and iv) 
activation method (collisional versus photoactivation). The two charge tags appended to the $\mathrm{N}$ terminus (TMPP and QA) modulated the fragmentation pathways in different ways, with the TMPP acting as a true fixed charge site and leading to dominant and exclusive formation of $\mathrm{N}$ terminal fragment ions, whereas the quaternary amine charge tag underwent cleavage from either peptide terminus to release a mobile proton in a manner noted previously by Reilly et al. $[12,13]$. For all peptides, whether containing a fixed charge site or not, the fragmentation patterns of the charge-reduced species (those created via electron transfer) resulted in clean production of $c$ and $z$ ions upon secondary activation of CAD, HCD, or UVPD. Hybrid activation spectra were remarkably similar for ETcaD, EThcD, and ETuvPD despite the well-established differences in the collisional activation and photoactivation processes. Although UVPD is well known to create rich fragmentation patterns for protonated peptides, this was not the case for UVPD of odd electron peptides, and instead the resulting spectra were much simpler than typical UVPD mass spectra and nearly identical to the spectra produced by ETD (c/z ions). The dominance of the radical-mediated fragmentation pathways underscored the overwhelming impact of the radical site, more-so than the presence of a fixed charge or the type of activation method used. From a practical standpoint, this outcome suggests a strategy for simplifying overly congested MS/MS spectra (particularly UVPD spectra) by incorporating an initial chargereduction step to consolidate fragmentation into $c / z$ ions.

\section{Acknowledgements}

Funding from the NSF (CHE-1402753) and the Welch Foundation (F-1155) is acknowledged. 


\section{References}

[1] T.E. Angel, U.K. Aryal, S.M. Hengel, E.S. Baker, R.T. Kelly, E.W. Robinson, R.D. Smith, Mass Spectrometry-Based Proteomics: Existing Capabilities and Future Directions, Chemical Society Reviews 41 (10) (2012) 3912-3928.

[2] Y. Zhang, B.R. Fonslow, B. Shan, M.C. Baek, J.R. Yates, Protein Analysis by Shotgun/Bottom-up Proteomics, Chemical Reviews 113 (4) (2013) 2343-2394.

[3] T.C. Walther, M. Mann. Mass Spectrometry-Based Proteomics in Cell Biology, The Journal of Cell Biology 190 (4) (2010) 491-500.

[4] F. Schütz, E.A. Kapp, R.J. Simpson, T.P. Speed, Deriving Statistical Models for Predicting Peptide Tandem MS Product Ion Intensities, Biochemical Society Transactions 31 (6) (2003) 1479-1483.

[5] V.H. Wysocki, G. Tsaprailis, L.L. Smith, L.A. Breci, Mobile and Localized Protons: A Framework for Understanding Peptide Dissociation, Journal of Mass Spectrometry 35 (12) (2000) 1399-1406.

[6] L.A. Breci, D.L. Tabb, J.R. Yates, V.H. Wysocki, Cleavage N-Terminal to Proline: Analysis of a Database of Peptide Tandem Mass Spectra, Analytical Chemistry 75 (9) (2003) 1963-1971.

[7] A.R, Dongré, J.L. Jones, Á. Somogyi, V.H. Wysocki, Influence of Peptide Composition, Gas-Phase Basicity, and Chemical Modification on Fragmentation Efficiency: Evidence for the Mobile Proton Model, Journal of the American Chemical Society 118 (35) (1996) 8365-8374.

[8] H. Steen, M. Mann, The Abc's (and Xyz's) of Peptide Sequencing, Nature Reviews Molecular Cell Biology 5 (9) (2004) 699-711.

[9] A.G. Sullivan, F.L. Brancia, R. Tyldesley, R. Bateman, K. Sidhu, S.J. Hubbard, S.G. Oliver, S.J. Gaskell, The Exploitation of Selective Cleavage of Singly Protonated Peptide Ions Adjacent to Aspartic Acid Residues Using a Quadrupole Orthogonal Time-of-Flight Mass Spectrometer Equipped with a Matrix-Assisted Laser Desorption/ionization Source, International Journal of Mass Spectrometry 210/211 (2001) 665-676.

[10] P.-C. Liao, J. Allison, Enhanced detection of peptides in matrix-assisted laser desorption/ionization mass spectrometry through the use of charge-localized derivatives, Journal of Mass Spectrometry. 30 (1995) 511-512.

[11] P.-C. Liao, Z.-H. Huang, J. Allison, Charge remote fragmentation of peptides following attachment of a fixed positive charge: A matrix-assisted laser desorption/ionization postsource decay study, Journal of the American Society for Mass Spectrometry. 8 (1997) 501-509.

[12] Y. He, J.P. Reilly, Does a Charge Tag Really Provide a Fixed Charge?, Angewandte Chemie International Edition. 47 (2008) 2463-2465.

[13] Y. He, R. Parthasarathi, K. Raghavachari, J.P. Reilly, Photodissociation of Charge Tagged Peptides, Journal of The American Society for Mass Spectrometry. 23 (2012) 1182-1190.

[14] M. Zimnicka, C. Moss, T. Chung, R. Hui, F. Tureček, Tunable Charge Tags for ElectronBased Methods of Peptide Sequencing: Design and Applications, Journal of The American Society for Mass Spectrometry. 23 (2012) 608-620.

[15] F. Kjeldsen, A.M.B. Giessing, C.R. Ingrell, O.N. Jensen, Peptide sequencing and characterization of post-translational modifications by enhanced ion-charging and liquid chromatography electron-transfer dissociation tandem mass spectrometry, Anal. Chem. 79 (2007) 9243-9252. 
[16] B.L. Frey, C.J. Krusemark, A.R. Ledvina, J.J. Coon, P.J. Belshaw, L.M. Smith, Ion-Ion Reactions with Fixed-Charge Modified Proteins to Produce lons in a Single, Very High Charge State, Int J Mass Spectrom. 276 (2008) 136-143.

[17] C. Krusemark, B. Frey, P. Belshaw, L. Smith, Modifying the charge state distribution of proteins in electrospray ionization mass spectrometry by chemical derivatization, J Am Soc Mass Spectrom. 20 (2009) 1617-1625.

[18] X.J. Li, J.J. Cournoyer, C. Lin, P.B. O'Connor, The Effect of Fixed Charge Modifications on Electron Capture Dissociation, J. Am. Soc. Mass Spectrom. 19 (2008) 1514-1526.

[19] J. Chamot-Rooke, G. van der Rest, A. Dalleu, S. Bay, J. Lemoine, The combination of electron capture dissociation and fixed charge derivatization increases sequence coverage for O-glycosylated and O-phosphorylated peptides, J. Am. Soc. Mass Spectrom. 18 (2007) 1405-1413.

[20] B.M. Ueberheide, D. Fenyo, P.F. Alewood, B.T. Chait, Rapid sensitive analysis of cysteine rich peptide venom components, Proc. Natl. Acad. Sci. U. S. A. 106 (2009) 6910-6915.

[21] H.P. Gunawardena, M. He, P.A. Chrisman, S.J. Pitteri, J.M. Hogan, B.D.M. Hodges, S.A. McLuckey, Electron Transfer versus Proton Transfer in Gas-Phase lon/lon Reactions of Polyprotonated Peptides, Journal of the American Chemical Society. 127 (2005) 1262712639.

[22] L. Zhang, Y. Xu, H. Lu, P. Yang, Carboxy group derivatization for enhanced electrontransfer dissociation mass spectrometric analysis of phosphopeptides, PROTEOMICS. 9 (2009) 4093-4097.

[23] L. Vasicek, J.S. Brodbelt, Enhanced Electron Transfer Dissociation through Fixed Charge Derivatization of Cysteines, Analytical Chemistry. 81 (2009) 7876-7884.

[24] Y. Lu, X. Zhou, P.M. Stemmer, G.E. Reid, Sulfonium Ion Derivatization, Isobaric Stable Isotope Labeling and Data Dependent CID- and ETD-MS/MS for Enhanced Phosphopeptide Quantitation, Identification and Phosphorylation Site Characterization, Journal of The American Society for Mass Spectrometry. 23 (2012) 577-593.

[25] T.W. Chung, C.L. Moss, M. Zimnicka, R.S. Johnson, R.L. Moritz, F. Tureček, ElectronCapture and -Transfer Dissociation of Peptides Tagged with Tunable Fixed-Charge Groups: Structures and Dissociation Energetics, Journal of The American Society for Mass Spectrometry. 22 (2011) 13-30.

[26] T.W. Chung, F. Tureček, Selecting fixed-charge groups for electron-based peptide dissociations, International Journal of Mass Spectrometry. 276 (2008) 127-135.

[27] Y. Xu, L. Zhang, H. Lu, P. Yang, Mass Spectrometry Analysis of Phosphopeptides after Peptide Carboxy Group Derivatization, Anal. Chem. 80 (2008) 8324-8328.

[28] N. Sadagopan, J.T. Watson, Investigation of the tris(trimethoxyphenyl)phosphonium acetyl charged derivatives of peptides by electrospray ionization mass spectrometry and tandem mass spectrometry, Journal of the American Society for Mass Spectrometry. 11 (2000) 107-119.

[29] N. Sadagopan, J.T. Watson, Mass spectrometric evidence for mechanisms of fragmentation of charge-derivatized peptides, Journal of the American Society for Mass Spectrometry. 12 (2001) 399-409.

[30] C. Morano, X. Zhang, L.D. Fricker, Multiple Isotopic Labels for Quantitative Mass Spectrometry, Analytical Chemistry. 80 (2008) 9298-9309.

[31] B.J. Ko, J.S. Brodbelt, Enhanced Electron Transfer Dissociation of Peptides Modified at C-terminus with Fixed Charges, Journal of The American Society for Mass Spectrometry. 23 (2012) 1991-2000. 
[32] J.A. Madsen, J.S. Brodbelt, Simplifying Fragmentation Patterns of Multiply Charged Peptides by N-Terminal Derivatization and Electron Transfer Collision Activated Dissociation, Analytical Chemistry. 81 (2009) 3645-3653.

[33] K.V. Wasslen, L.H. Tan, J.M. Manthorpe, J.C. Smith, Trimethylation Enhancement using Diazomethane (TrEnDi): Rapid On-Column Quaternization of Peptide Amino Groups via Reaction with Diazomethane Significantly Enhances Sensitivity in Mass Spectrometry Analyses via a Fixed, Permanent Positive Charge, Analytical Chemistry. 86 (2014) 3291 3299.

[34] R.A. Zubarev, N.L. Kelleher, F.W. McLafferty, Electron Capture Dissociation of Multiply Charged Protein Cations. A Nonergodic Process, Journal of the American Chemical Society. 120 (1998) 3265-3266.

[35] F.W. McLafferty, D.M. Horn, K. Breuker, Y. Ge, M.A. Lewis, B. Cerda, R.A. Zubarev, B.K. Carpenter, Electron capture dissociation of gaseous multiply charged ions by Fouriertransform ion cyclotron resonance, Journal of the American Society for Mass Spectrometry. 12 (2001) 245-249.

[36] J.E.P. Syka, J.J. Coon, M.J. Schroeder, J. Shabanowitz, D.F. Hunt, Peptide and protein sequence analysis by electron transfer dissociation mass spectrometry, Proceedings of the National Academy of Sciences of the United States of America. 101 (2004) 95289533.

[37] S.A. McLuckey, J.L. Stephenson, lon/ion chemistry of high-mass multiply charged ions, Mass Spectrometry Reviews. 17 (1998) 369-407.

[38] D.L. Swaney, G.C. McAlister, M. Wirtala, J.C. Schwartz, J.E.P. Syka, J.J. Coon, Supplemental Activation Method for High-Efficiency Electron-Transfer Dissociation of Doubly Protonated Peptide Precursors, Analytical Chemistry. 79 (2007) 477-485.

[39] D.M. Horn, Y. Ge, F.W. McLafferty, Activated Ion Electron Capture Dissociation for Mass Spectral Sequencing of Larger (42 kDa) Proteins, Analytical Chemistry. 72 (2000) 47784784.

[40] A.T. lavarone, J.C. Jurchen, E.R. Williams, Supercharged Protein and Peptide lons Formed by Electrospray lonization, Analytical Chemistry. 73 (2001) 1455-1460.

[41] A.T. lavarone, E.R. Williams, Supercharging in electrospray ionization: effects on signal and charge, International Journal of Mass Spectrometry. 219 (2002) 63-72.

[42] A.T. lavarone, E.R. Williams, Collisionally activated dissociation of supercharged proteins formed by electrospray ionization, Anal. Chem. 75 (2003) 4525-4533.

[43] J.A. Madsen, J.S. Brodbelt, Comparison of infrared multiphoton dissociation and collisioninduced dissociation of supercharged peptides in ion traps, J. Am. Soc. Mass Spectrom. 20 (2009) 349-358.

[44] J.R. Cannon, D.D. Holden, J.S. Brodbelt, Hybridizing Ultraviolet Photodissociation with Electron Transfer Dissociation for Intact Protein Characterization, Analytical Chemistry. 86 (2014) 10970-10977.

[45] A.R. Ledvina, C.M. Rose, G.C. McAlister, J.E.P. Syka, M.S. Westphall, J. Griep-Raming, J.C. Schwartz, J.J. Coon, Activated Ion ETD Performed in a Modified Collision Cell on a Hybrid QLT-Orbitrap Mass Spectrometer, Journal of The American Society for Mass Spectrometry. 24 (2013) 1623-1633.

[46] C.K. Frese, A.F.M. Altelaar, H. van den Toorn, D. Nolting, J. Griep-Raming, A.J.R. Heck, $\mathrm{S}$. Mohammed, Toward Full Peptide Sequence Coverage by Dual Fragmentation Combining Electron-Transfer and Higher-Energy Collision Dissociation Tandem Mass Spectrometry, Analytical Chemistry. 84 (2012) 9668-9673.

[47] A.R. Ledvina, G.C. McAlister, M.W. Gardner, S.I. Smith, J.A. Madsen, J.C. Schwartz, G.C. Stafford, J.E.P. Syka, J.S. Brodbelt, J.J. Coon, Infrared Photoactivation Reduces 
Peptide Folding and Hydrogen-Atom Migration following ETD Tandem Mass Spectrometry, Angewandte Chemie International Edition. 48 (2009) 8526-8528.

[48] C.K. Frese, H. Zhou, T. Taus, A.F.M. Altelaar, K. Mechtler, A.J.R. Heck, S. Mohammed, Unambiguous Phosphosite Localization using Electron-Transfer/Higher-Energy Collision Dissociation (EThcD), Journal of Proteome Research. 12 (2013) 1520-1525.

[49] A.M. Brunner, P. Lössl, F. Liu, R. Huguet, C. Mullen, M. Yamashita, V. Zabrouskov, A. Makarov, A.F.M. Altelaar, A.J.R. Heck, Benchmarking Multiple Fragmentation Methods on an Orbitrap Fusion for Top-down Phospho-Proteoform Characterization, Analytical Chemistry. 87 (2015) 4152-4158.

[50] C.J. Shaffer, A. Marek, R. Pepin, K. Slovakova, F. Turecek, Combining UV photodissociation with electron transfer for peptide structure analysis: ETD photodissociation, Journal of Mass Spectrometry. 50 (2015) 470-475.

[51] S.I. Smith, J.S. Brodbelt, Hybrid Activation Methods for Elucidating Nucleic Acid Modifications, Analytical Chemistry. 83 (2011) 303-310.

[52] J.A. Madsen, R.R. Cheng, T.S. Kaoud, K.N. Dalby, D.E. Makarov, J.S. Brodbelt, ChargeSite-Dependent Dissociation of Hydrogen-Rich Radical Peptide Cations upon Vacuum UV Photoexcitation, Chemistry - A European Journal. 18 (2012) 5374-5383.

[53] H.T.H. Nguyen, C.J. Shaffer, A.R. Ledvina, J.J. Coon, F. Tureček, Serine effects on collision-induced dissociation and photodissociation of peptide cation radicals of the $\mathrm{z}+\bullet-$ type, International Journal of Mass Spectrometry. 378 (2015) 20-30.

[54] H.T.H. Nguyen, C.J. Shaffer, F. Tureček, Probing Peptide Cation-Radicals by Near-UV Photodissociation in the Gas Phase. Structure Elucidation of Histidine Radical Chromophores Formed by Electron Transfer Reduction, The Journal of Physical Chemistry B. 119 (2015) 3948-3961.

[55] J.B. Shaw, W. Li, D.D. Holden, Y. Zhang, J. Griep-Raming, R.T. Fellers, B.P. Early, P.M. Thomas, N.L. Kelleher, J.S. Brodbelt, Complete Protein Characterization Using TopDown Mass Spectrometry and Ultraviolet Photodissociation, J. Am. Chem. Soc. 135 (2013) 12646-12651.

[56] J.R. Cannon, M.B. Cammarata, S.A. Robotham, V.C. Cotham, J.B. Shaw, R.T. Fellers, B.P. Early, P.M. Thomas, N.L. Kelleher, J.S. Brodbelt, Ultraviolet Photodissociation for Characterization of Whole Proteins on a Chromatographic Time Scale, Analytical Chemistry. 86 (2014) 2185-2192.

[57] S. Warnke, C. Baldauf, M.T. Bowers, K. Pagel, G. von Helden, Photodissociation of Conformer-Selected Ubiquitin Ions Reveals Site-Specific Cis / Trans Isomerization of Proline Peptide Bonds, Journal of the American Chemical Society. 136 (2014) 1030810314.

[58] J.R. Cannon, C. Kluwe, A. Ellington, J.S. Brodbelt, Characterization of green fluorescent proteins by $193 \mathrm{~nm}$ ultraviolet photodissociation mass spectrometry, PROTEOMICS. 14 (2014) 1165-1173.

[59] J.A. Madsen, D.R. Boutz, J.S. Brodbelt, Ultrafast Ultraviolet Photodissociation at $193 \mathrm{~nm}$ and its Applicability to Proteomic Workflows, Journal of Proteome Research. 9 (2010) 4205-4214.

[60] M. Cammarata, K.-Y. Lin, J. Pruet, H. Liu, J. Brodbelt, Probing the Unfolding of Myoglobin and Domain $\mathrm{C}$ of PARP-1 with Covalent Labeling and Top-Down Ultraviolet Photodissociation Mass Spectrometry, Analytical Chemistry. 86 (2014) 2534-2542.

[61] J.R. Cannon, D.D. Holden, J.S. Brodbelt, Hybridizing Ultraviolet Photodissociation with Electron Transfer Dissociation for Intact Protein Characterization, Analytical Chemistry. 86 (2014) 10970-10977. 
[62] M.B. Cammarata, J.S. Brodbelt, Structural characterization of holo- and apo-myoglobin in the gas phase by ultraviolet photodissociation mass spectrometry, Chem. Sci. 6 (2015) 1324-1333.

[63] J.R. Cannon, K. Martinez-Fonts, S.A. Robotham, A. Matouschek, J.S. Brodbelt, TopDown 193-nm Ultraviolet Photodissociation Mass Spectrometry for Simultaneous Determination of Polyubiquitin Chain Length and Topology, Analytical Chemistry. 87 (2015) 1812-1820.

[64] N. Webber, Y. He, J.P. Reilly, $157 \mathrm{~nm}$ Photodissociation of Dipeptide lons Containing NTerminal Arginine, Journal of The American Society for Mass Spectrometry. 25 (2014) 196-203.

[65] L. Zhang, J.P. Reilly, Peptide Photodissociation with $157 \mathrm{~nm}$ Light in a Commercial Tandem Time-of-Flight Mass Spectrometer, Anal. Chem. 81 (2009) 7829-7838.

[66] T.-Y. Kim, J.P. Reilly, Time-resolved observation of product ions generated by $157 \mathrm{~nm}$ photodissociation of singly protonated phosphopeptides, J. Am. Soc. Mass Spectrom. 20 (2009) 2334-2341.

[67] S.H. Yoon, J.H. Moon, M.S. Kim, Dissociation mechanisms and implication for the presence of multiple conformations for peptide ions with arginine at the C-terminus: timeresolved photodissociation study, Journal of Mass Spectrometry. 45 (2010) 806-814.

[68] S.H. Yoon, J.H. Moon, Y.J. Chung, M.S. Kim, Influence of basic residues on dissociation kinetics and dynamics of singly protonated peptides: time-resolved photodissociation study, Journal of Mass Spectrometry. 44 (2009) 1532-1537.

[69] J.H. Moon, Y.S. Shin, H.J. Cha, M.S. Kim, Photodissociation at $193 \mathrm{~nm}$ of some singly protonated peptides and proteins with $\mathrm{m} / \mathrm{z} 2000-9000$ using a tandem time-of-flight mass spectrometer equipped with a second source for delayed extraction/post-acceleration of product ions, Rapid Commun. Mass Spectrom. 21 (2007) 359-368.

[70] S.M. Greer, J.R. Cannon, J.S. Brodbelt, Improvement of Shotgun Proteomics in the Negative Mode by Carbamylation of Peptides and Ultraviolet Photodissociation Mass Spectrometry, Analytical Chemistry. 86 (2014) 12285-12290.

[71] J.P. O'Brien, W. Li, Y. Zhang, J.S. Brodbelt, Characterization of Native Protein Complexes Using Ultraviolet Photodissociation Mass Spectrometry, Journal of the American Chemical Society. 136 (2014) 12920-12928.

[72] M.R. Robinson, K.L. Moore, J.S. Brodbelt, Direct Identification of Tyrosine Sulfation by using Ultraviolet Photodissociation Mass Spectrometry, Journal of The American Society for Mass Spectrometry. 25 (2014) 1461-1471.

[73] S.H. Yoon, Y.J. Chung, M.S. Kim, Time-resolved photodissociation of singly protonated peptides with an arginine at the $\mathrm{N}$-terminus: A statistical interpretation, Journal of the American Society for Mass Spectrometry. 19 (2008) 645-655.

[74] Q. Sun, H. Nelson, T. Ly, B.M. Stoltz, R.R. Julian, Side Chain Chemistry Mediates Backbone Fragmentation in Hydrogen Deficient Peptide Radicals, Journal of Proteome Research. 8 (2009) 958-966.

[75] R. Marchese, R. Grandori, P. Carloni, S. Raugei, On the Zwitterionic Nature of GasPhase Peptides and Protein lons, PLoS Computational Biology, 6 (2010), e1000775.

[76] F. Kjeldsen, O.A. Silivra, R.A. Zubarev, Zwitterionic States in Gas-Phase Polypeptide lons Revealed by 157-nm Ultra-Violet Photodissociation, Chemistry - A European Journal. 12 (2006) 7920-7928. 
A)

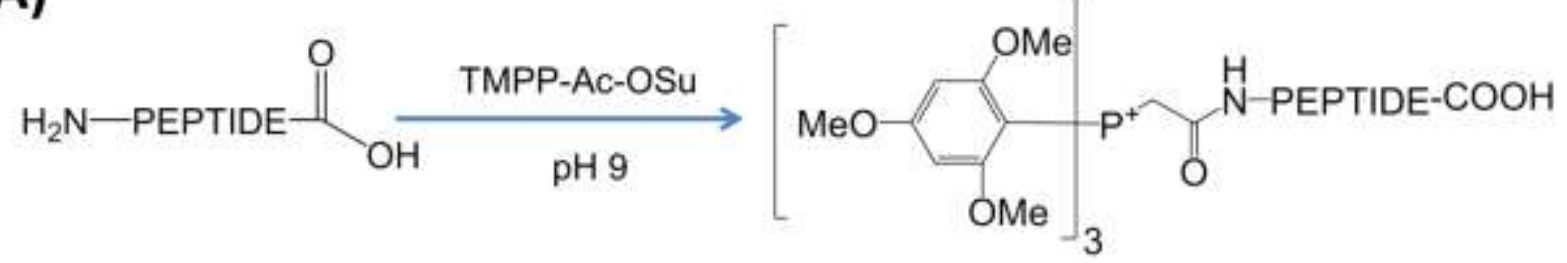

B)<smiles></smiles><smiles>CN(C)CCCC(=O)OC1CCC(O)C1OCCO</smiles><smiles>C[N+](C)(C)CCCC(O)NP=[PH2]CO[OH2+]</smiles>

C)

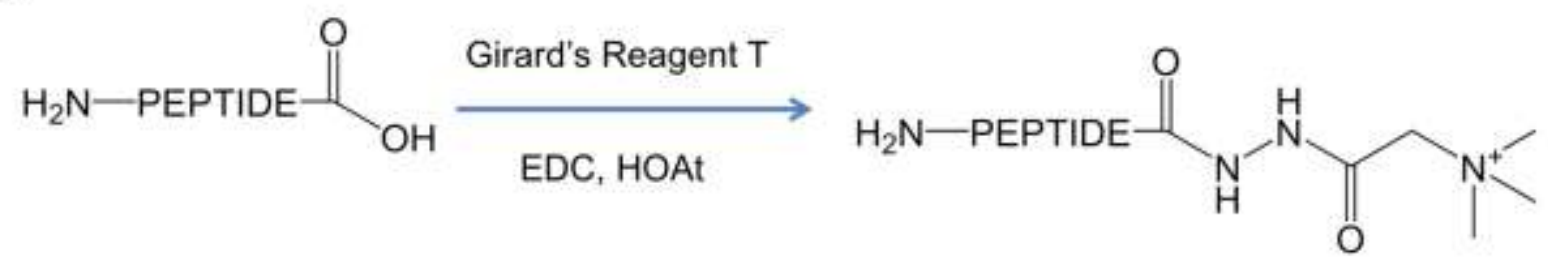

Scheme 1. A) Attachment of phosphonium fixed charge to the N-terminus of a peptide, B) attachment of a quaternary amine fixed charge to the $\mathrm{N}$-terminus of a peptide, and C) attachment of a quaternary amine fixed charge to the C-terminus of a peptide. 


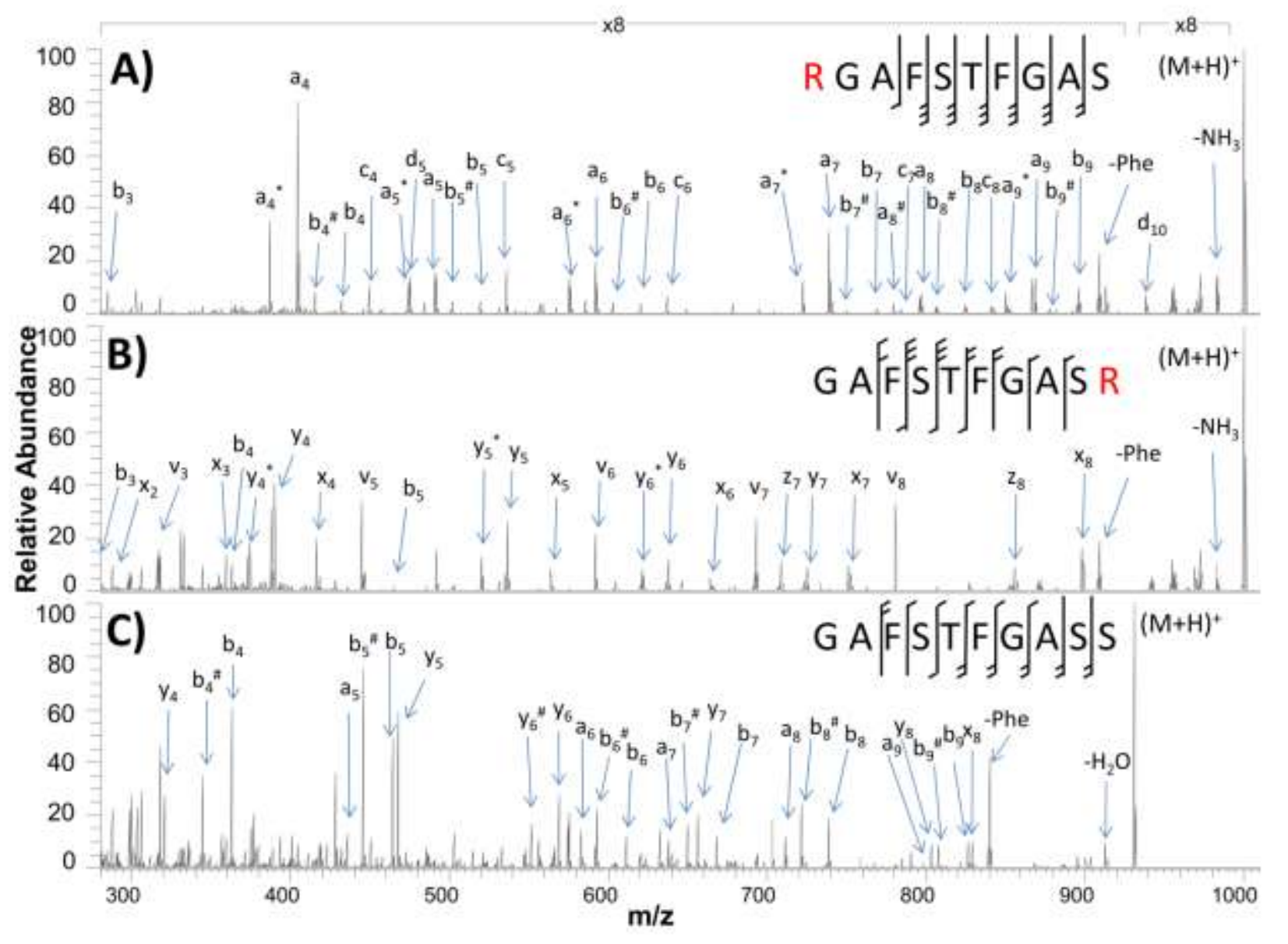

Figure 1. UVPD of protonated peptides: A) RGAFSTFGAS, showing mainly N-terminal fragments, B) GAFSTFGASR, showing mainly C-terminal fragments, and C) GAFSTFGASS, showing a mixture of both $\mathrm{N}$ and C-terminal fragments. All spectra have the same magnification scale (x8). \# = water loss, $*=$ ammonia loss. 


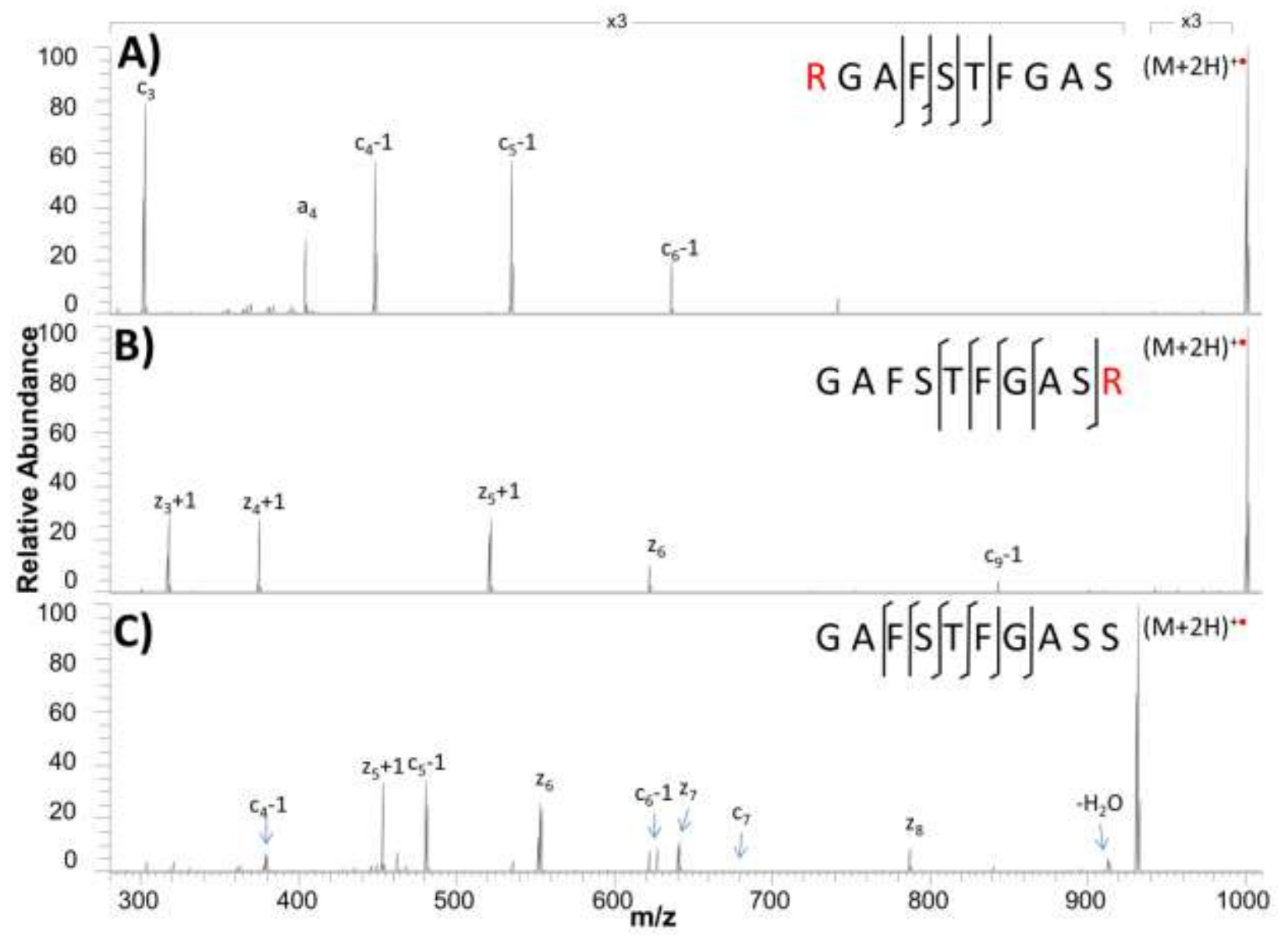

Figure 2. ETuvPD of protonated charge-reduced peptides: A) RGAFSTFGAS, showing mainly N-terminal fragments, B) GAFSTFGASR, showing mainly C-terminal fragments, and C) GAFSTFGASS, showing a mixture of both $\mathrm{N}$ and $\mathrm{C}$-terminal fragments. All spectra have the same magnification scale (x3). 


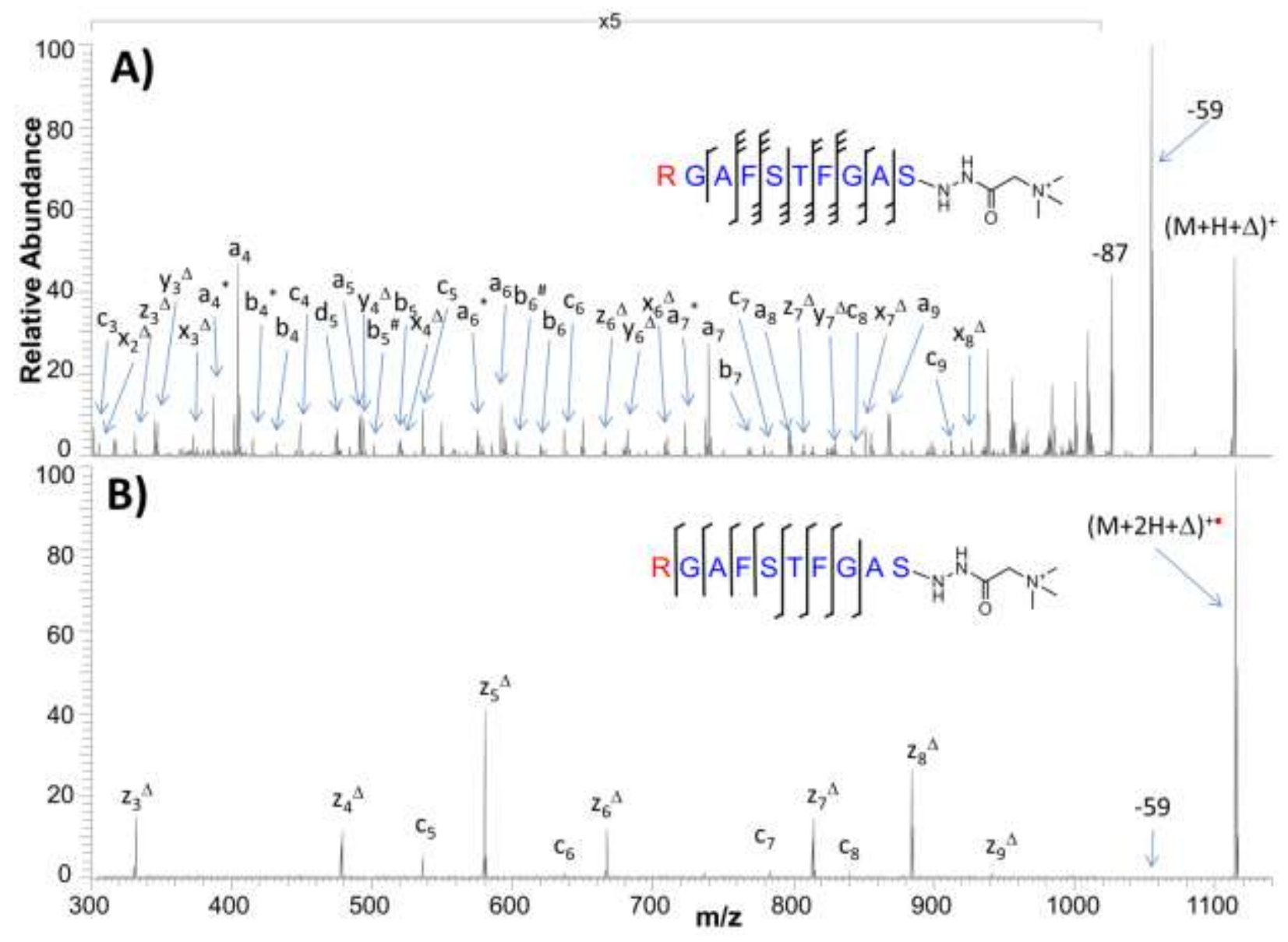

Figure 3. A) UVPD of +1 ion of C-terminal fixed-charge peptide RGAFSTFGAS-QA ${ }^{+}$showing dominant loss of trimethylamine, and B) ETuvPD of charge-reduced species of Cterminal fixed-charge peptide RGAFSTFGAS-QA ${ }^{+}$simplified fragmentation. $\Delta=$ ions containing fixed-charge tag. All spectra have the same magnification scale (x5). \# = water loss, $*=$ ammonia loss. 

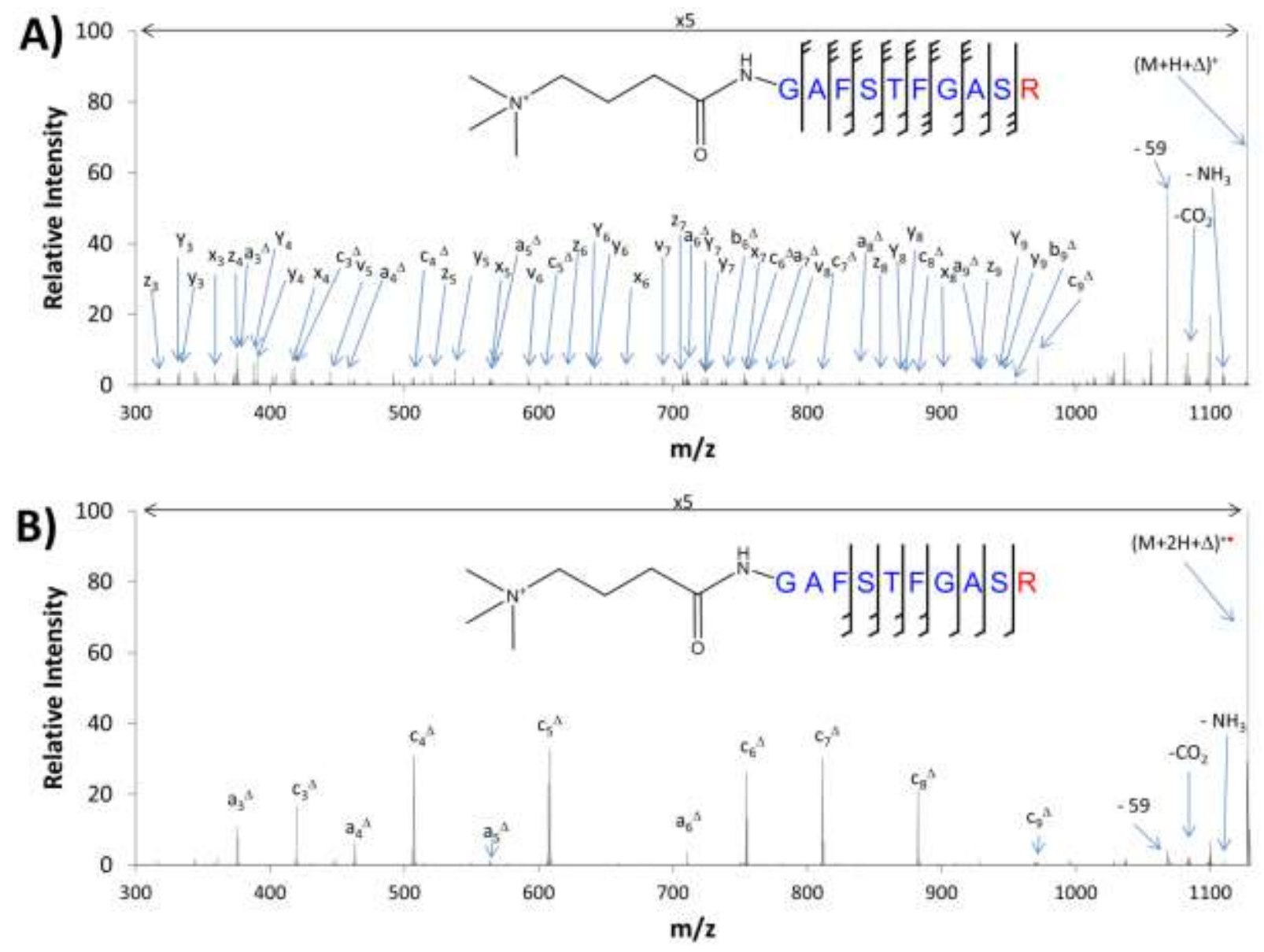

Figure 4. A) UVPD of A) +1 ion of $N$-terminal fixed-charge peptide $\mathrm{QA}^{+}$-GAFSTFGASR, and B) ETuvPD of charge-reduced species of N-terminal fixed-charge peptide $\mathrm{QA}^{+}-$ GAFSTFGASR showing simplified fragmentation. $\Delta=$ ions containing fixedcharge tag. 

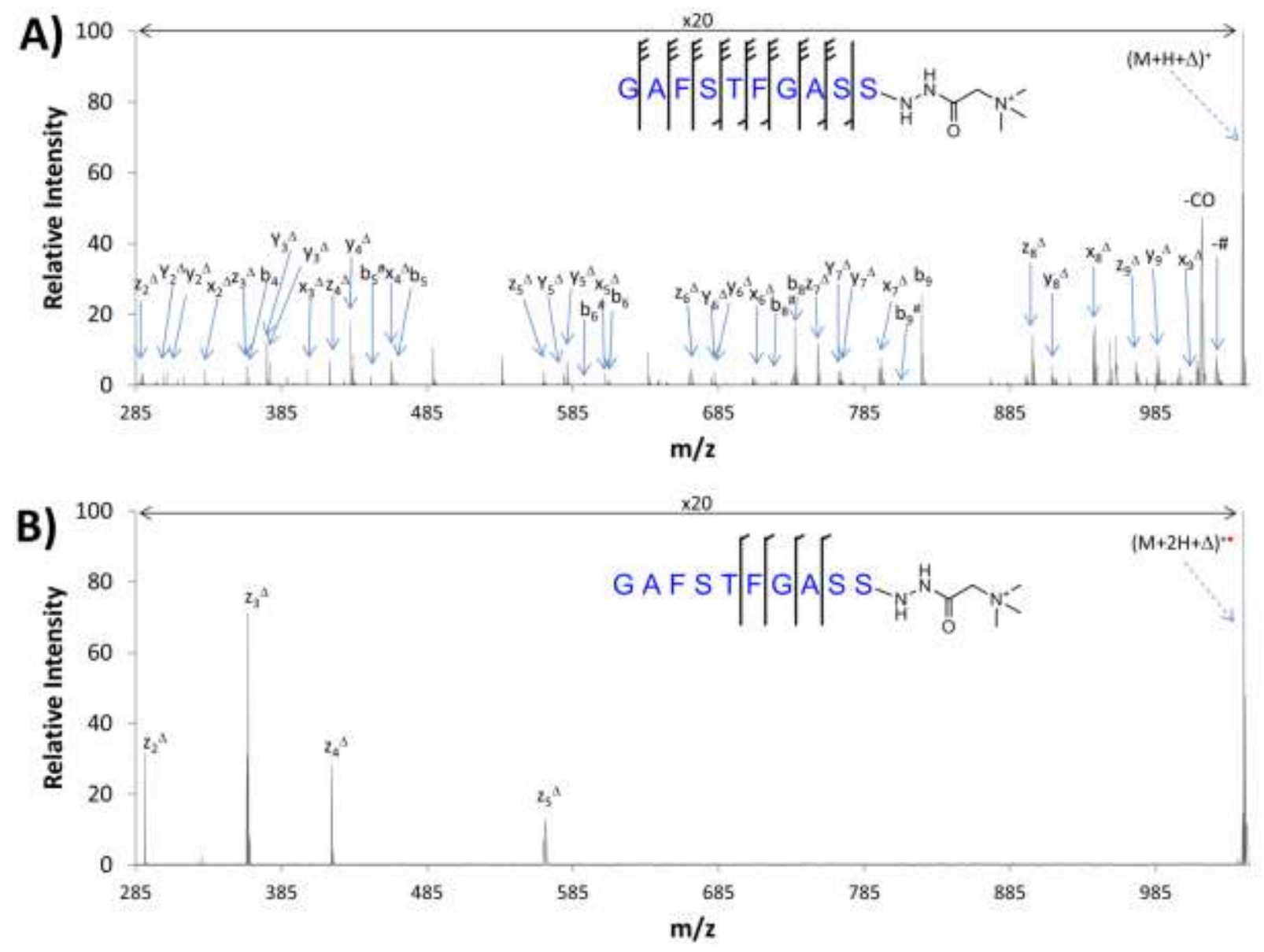

Figure 5. A) UVPD of A) +1 ion of C-terminal fixed-charge peptide GAFSTFGASS-QA ${ }^{+}$, and B) ETuvPD of charge-reduced species of C-terminal fixed-charge peptide GAFSTFGASS-QA ${ }^{+}$showing simplified fragmentation. $\#=$ water loss, ${ }^{*}=$ ammonia loss, and $\Delta=$ ions containing the fixed-charge tag. 


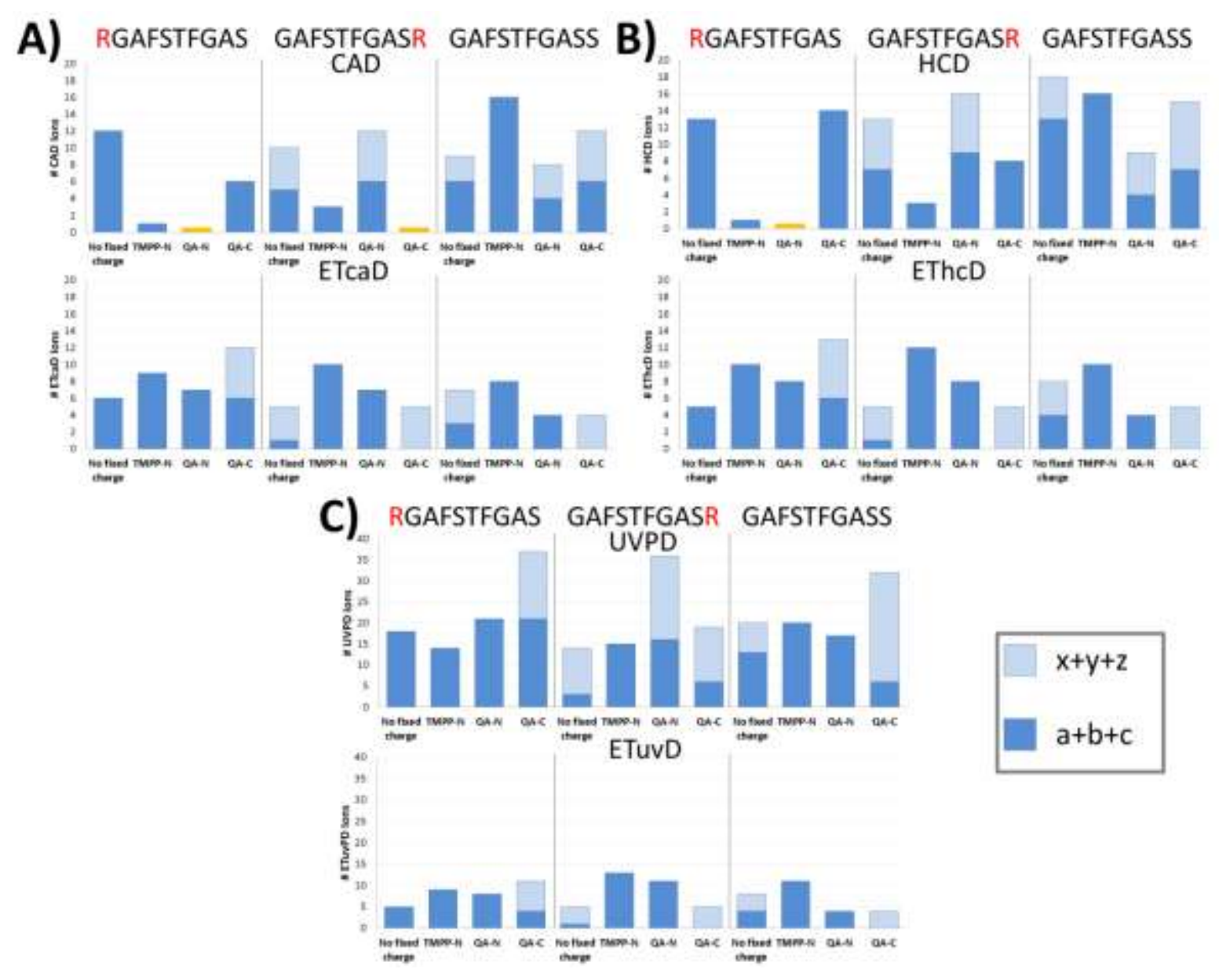

Figure 6. Number of fragment ions identified for peptides RGAFSTFGAS, GAFSTFGASR, and GAFSTFGASS with no fixed charge, TMPP N-terminal fixed charge (TMPP-N), quaternary amine N-terminal fixed charge (QA-N), and quaternary amine Cterminal fixed charge (QA-C). A) CAD versus ETcaD, B) HCD versus EThcD, and C) UVPD versus ETuvPD. Light blue bars represent $\mathrm{C}$-terminal $(\mathrm{x}, \mathrm{y}, \mathrm{z})$ fragment ion types and dark blue bars represent $\mathrm{N}$-terminal $(\mathrm{a}, \mathrm{b}, \mathrm{c})$ fragment ion types. The gold bars indicate that no fragments were identified. Note that the scale of the $y-$ axis in $\mathrm{C}$ is double the scale of $\mathrm{A}$ and $\mathrm{B}$. 
TOC Graphic

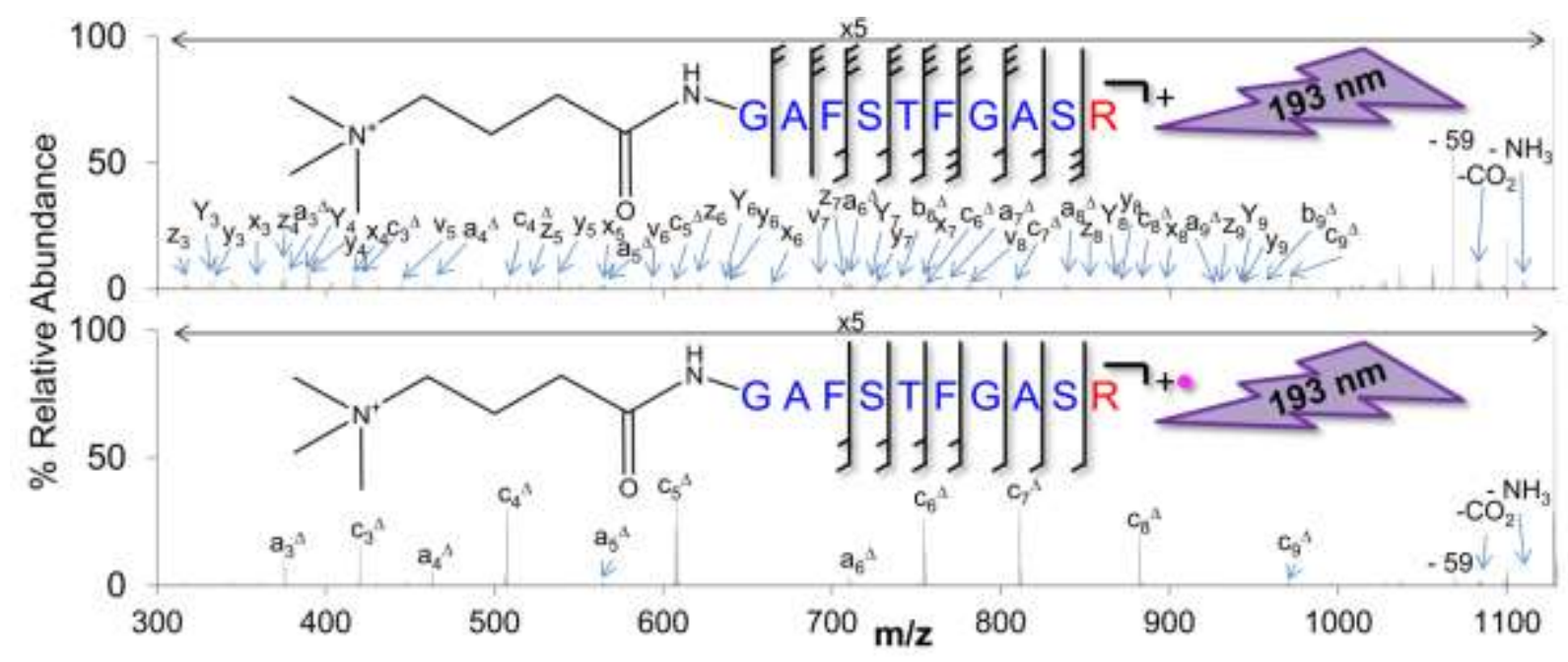

